\title{
EXPRESSION OF CLASSICAL MEDIATORS IN HEARTS OF RATS WITH HEPATIC DYSFUNCTION
}

\begin{tabular}{|c|c|}
\hline Journal: & Canadian Journal of Physiology and Pharmacology \\
\hline Manuscript ID & cjpp-2017-0060.R1 \\
\hline Manuscript Type: & Article \\
\hline Date Submitted by the Author: & 28-Mar-2017 \\
\hline Complete List of Authors: & $\begin{array}{l}\text { Jarkovska, Dagmar; Charles University, Medical Faculty in Pilsen, } \\
\text { Biomedical Center; Charles University, Medical Faculty in Pilsen, Dep. of } \\
\text { Physiology } \\
\text { Bludovska, Monika; Charles University, Faculty of Medicine in Pilsen, } \\
\text { Biomedical Center; Charles University, Faculty of Medicine in Pilsen, Dep. } \\
\text { of Pharmacology and Toxicology } \\
\text { Mistrova, Eliska; Charles University, Faculty of Medicine in Pilsen, } \\
\text { Biomedical Center; Charles University, Faculty of Medicine in Pilsen, Dep. } \\
\text { of Physiology } \\
\text { Krizkova, Vera; Charles University, Faculty of Medicine in Pilsen, Dep. of } \\
\text { Histology and Embryology } \\
\text { Kotyzova, Dana; Charles University, Faculty of Medicine in Pilsen, Dep. of } \\
\text { Pharmacology and Toxicology } \\
\text { Kubikova, Tereza; Charles University, Faculty of Medicine in Pilsen, } \\
\text { Biomedical Center; Charles University, Faculty of Medicine in Pilsen, Dep. } \\
\text { of Histology and Embryology } \\
\text { Slavikova, Jana; Charles University, Faculty of Medicine in Pilsen, } \\
\text { Biomedical Center } \\
\text { Erek, Sumeyye Nur; Charles University, Faculty of Medicine in Pilsen, Dep. } \\
\text { of Physiology } \\
\text { Djordjevic, Aleksandar; Charles University, Faculty of Medicine in Pilsen, } \\
\text { Dep. of Physiology } \\
\text { Chottova Dvorakova, Magdalena; Charles University, Faculty of Medicine in } \\
\text { Pilsen, Biomedical Center; Charles University, Faculty of Medicine in Pilsen, } \\
\text { Dep. of Physiology }\end{array}$ \\
\hline $\begin{array}{r}\text { Is the invited manuscript for } \\
\text { consideration in a Special } \\
\text { Issue?: }\end{array}$ & IACS European Section 2016 \\
\hline Keyword: & $\begin{array}{l}\text { cirrhotic cardiomyopathy, thioacetamide, bile duct ligation, heart, } \\
\text { intracardiac nervous system, catecholamines, lipid peroxidat }\end{array}$ \\
\hline
\end{tabular}


SCHOLARONE $^{\text {m }}$
Manuscripts

https://mc06.manuscriptcentral.com/cjpp-pubs 
EXPRESSION OF CLASSICAL MEDIATORS IN HEARTS OF RATS WITH HEPATIC DYSFUNCTION

Dagmar Jarkovska $^{1,2}$, Monika Bludovska ${ }^{1,3}$, Eliska Mistrova ${ }^{1,2}$, Vera Krizkova ${ }^{4}$, Dana Kotyzova $^{3}$, Tereza Kubikova ${ }^{1,4}$, Jana Slavikova $^{1}$, Sumeyye Nur Erek ${ }^{2}$, Aleksandar Djordjevic $^{2}$, and Magdalena Chottova Dvorakova ${ }^{1,2}$

${ }^{1}$ Biomedical Center, Faculty of Medicine in Pilsen, Charles University, alej Svobody 1655/76, 32300 Pilsen, Czech Republic

${ }^{2}$ Department of Physiology, Faculty of Medicine in Pilsen, Charles University, alej Svobody 1655/76, 32300 Pilsen, Czech Republic

${ }^{3}$ Department of Pharmacology and Toxicology, Faculty of Medicine in Pilsen, Charles University, alej Svobody 1655/76, 32300 Pilsen, Czech Republic

${ }^{4}$ Department of Histology and Embryology, Faculty of Medicine in Pilsen, Charles University, Lidicka 1, 32300 Pilsen, Czech Republic

Corresponding author's address:

Magdalena Chottova Dvorakova, Biomedical Center, Faculty of Medicine in Pilsen, Charles University, alej Svobody 1655/76, 32300 Pilsen, Czech Republic

Phone number: +420 377593343

E-mail address: magdalena.dvorakova@1fp.cuni.cz 


\begin{abstract}
Liver cirrhosis is associated with impairment of cardiovascular function including alterations of the heart innervation, humoral and nervous dysregulation, changes in systemic circulation and electrophysiological abnormalities. Choline acetyltransferase (ChAT), enzyme forming acetylcholine, tyrosine hydroxylase (TH) and dopamine- $\beta$-hydroxylase (DBH), enzymes participating in noradrenaline synthesis, are responsible for the production of classical neurotransmitters and atrial natriuretic peptide (ANP) is produced by cardiomyocytes. The aim of this study was to evaluate the influence of experimentally induced hepatic dysfunction on the expression of proANP, ChAT, TH and DBH in the heart. Hepatic dysfunction was induced by application of thioacetamide (TAA) or by ligation of bile duct. Biochemical parameters of hepatic injury and levels of peroxidation in the liver and heart were measured. Liver enzymes measured in the plasma were significantly elevated. Cardiac level of peroxidation was increased in operated but not TAA group animals. In the left atrium of operated rats, the expression of TH and DBH was lower, while expression of ChAT remained unchanged. In TAA group, no significant differences in the expression of the genes compared to controls were observed. Liver injury induced by ligation leads to an imbalance in the intracardiac innervation, which might impair nervous control of the heart.
\end{abstract}

Key words: cirrhotic cardiomyopathy, thioacetamide, bile duct ligation, heart, intracardiac nervous system, catecholamines, lipid peroxidation. 


\section{Introduction}

Liver cirrhosis is associated with impairment of cardiovascular function including abnormal hemodynamics and latent heart failure termed "cirrhotic cardiomyopathy", which is characterized by altered diastolic relaxation, electrophysiological abnormalities, such as prolongation of QT interval and impaired contractility under physiological or pharmacological stress (Karagiannakis et al. 2015). Cardiac dysfunction is considered to be multifactorial and various mechanisms have been suggested to explain the cardiovascular abnormalities. Recent studies indicate that a blunted cardiac function is at least partially caused by an increased activity of vasodilatory pathways, changes in $\beta$-receptor and calcium signaling, altered cardiomyocytes membrane function, and elevated sympathetic nervous tone (Karagiannakis et al. 2015; Liu et al. 2006). Additionally, blunted responsiveness of muscarinic receptors in cirrhotic hearts has been demonstrated (Jaue et al. 1997). These findings indicate a possible role of the autonomic nervous system (ANS) in cirrhotic cardiomyopathy.

Alteration of the ANS functions including impairment of the cardiovascular autonomic reflexes has been reported in patients with chronic liver disease (Dumcke and Moller 2008). Reduced heart rate variability together with autonomic dysfunction of both sympathetic and parasympathetic components of heart innervation suggests damage of this innervation.

The aim of this study was to evaluate (a) whether this impairment is associated with abnormal expression of classical neurotransmitters in the heart ganglia and (b) whether etiology of the liver failure plays a role in it. Messenger RNA for tyrosine hydroxylase (TH) and dopamine- $\beta$-hydroxylase (DBH), enzymes participating in the synthesis of the principal neurotransmitter of the sympathetic division of the heart innervation noradrenaline (NA), and mRNA for choline acetyltransferase (ChAT), enzyme forming the principal neurotransmitter of the parasympathetic division acetylcholine $(\mathrm{ACh})$, have been studied. For this purpose, we 
used the two widely used rat models of liver failure caused either by chronic application of thioacetamide (TAA) or by common bile duct ligation (BDL), which both result in a wellcharacterized liver cirrhosis (Marques et al. 2012; Wallace et al. 2015). TAA is a thionosulfur-containing compound generating liver damage. Shortly after administration, it undergoes an extensive metabolism to thioacetamide-S-oxide, which is obligatory responsible for the hepatotoxic effect of this compound (Wallace et al. 2015), whereas it does not induce changes in other organs such as lung, or heart (Dashti et al. 1989).

Biochemical parameters of a hepatic injury were measured. Enzymes, alanine transaminase (ALT) and glutamate dehydrogenase (GLDH), were determined in the serum to evaluate the liver function. Lipid peroxidation (LP) and activities of glutathione peroxidase (GPx) were estimated in the liver and heart homogenates to verify tissue oxidative damage.

\section{Material and methods}

All experiments were approved by the University Committee for Experiments on Laboratory Animals and were conducted in accordance with the "Guide for the Care and Use of Laboratory Animals" (NIH Publication No. 85-23, revised 1996) as well as the relevant Guidelines of the Czech Ministry of Agriculture for scientific experimentation on animals. Experimental animals

Adult male Wistar rats purchased from VELAZ (Prague, Czech Republic) were used. The animals were housed five per cage, fed standard laboratory chow ad libitum with free access to drinking water. All animals were left intact to adapt for 2 weeks before the initiation of the experiments. Thirty rats were randomly divided into the control group (CO; 10 rats), TAA group (10 rats) and BDL group (10 rats). Rats from TAA group received intraperitoneal injection of TAA $(200 \mathrm{mg} / \mathrm{kg})$ in $0.9 \%$ normal saline three times per week over a period of 12 weeks as reported earlier (Bludovska et al. 2013; Natarajan et al. 2006). Control rats received 
vehicle alone. Rats were weighed prior to each injection to accurately calculate the dosage of TAA. BDL was done under ketamine $(100 \mathrm{mg} / \mathrm{kg}$ intramuscularly, Narketan, Vétoquinol, Nymburk, Czech Republic) and xylazin anesthesia (5 mg/kg intramuscularly; Rometar, Bioveta, Ivanovice na Hane, Czech Republic) by the double ligature and section of the common bile duct. Marbofloxacinum (5 mg/kg subcutaneously; Marbocyl, Véetoquinol, Nymburk, Czech Republic) was administered postoperatively for prophylaxis of infection. Cirrhosis was verified by the liver histology and biochemistry.

The animals were killed by decapitation 8 weeks after termination of TAA treatment or BDL. Heart and liver were rapidly excised, dried with filter paper, and weighed on a precision balance. Cardiac and liver weight indexes were calculated as the ratio of organ to body weight.

\section{Histopathology}

Liver specimens, approximately $1.5 \mathrm{~cm}^{3}(n=5 ; 2$ specimens from the left lateral lobe and 3 specimens from the left medial lobe) from each animal were removed, fixed with buffered formalin, dehydrated in graded ethanol solutions and embedded in paraffin blocks.

All blocks were cut into 4-5- $\mu$ m-thick histological sections and stained with hematoxylin and eosin (HE). The selected liver specimen - the middle part of left medial lobe - from each animal was documented and processed as follows: picrosirius red (PSR; Direct Red 80, Sigma Aldrich, Munich, Germany) diluted in saturated picric acid solution was used to visualize the type I collagen using circularly polarized light (Rich et al. 2005). The sections were analyzed using microscope Nikon Eclipse Ti-U (Nicon Corporation, Yokohama, Japan) equipped with filters to provide above mentioned polarized illumination and recorded on a camera DS-Fi2 with high resolution image capture. Tissue images were obtained with a $4 \mathrm{X}$ (picrosirius red), 20X and 40X (HE) objective lenses.

Biochemical analysis of serum, liver and heart 
Blood and tissue samples were collected and used immediately or stored frozen at $70^{\circ} \mathrm{C}$ until analyzed. LP and activities of GPx were estimated in the liver and heart homogenates. Activities of ALT, and GLDH were determined in the serum.

LP was estimated in tissue homogenates by measuring the products formed in the thiobarbituric acid (TBA) reaction (Mihara and Uchiyama 1978). Tissue homogenates (0.25 $\mathrm{g} / 2.5 \mathrm{ml}$ of $1.15 \%$ potassium chloride $(\mathrm{KCl})$ ) were mixed with $1.5 \mathrm{ml}$ of $1 \%$ phosphoric acid $\left(\mathrm{H}_{3} \mathrm{PO}_{4}\right)$ and $0.5 \mathrm{ml}$ of $0.6 \%$ TBA aqueous solution. The samples were heated at $95^{\circ} \mathrm{C}$ for 1 hour. After cooling, $2 \mathrm{ml}$ of n-butanol were added, mixed vigorously and the butanol phase was separated by centrifugation. The absorbance of butanol layer was measured at 520 and $535 \mathrm{~nm}$; the difference between the determinations was used to calculate concentration of TBA reactive substances (TBARS). The results are expressed in nmol of malondialdehyde (MDA)/gram of tissue.

GPx activity was assayed in tissue homogenates by a coupled test system, in which GR was employed for the regeneration of reduced glutathione and butyl hydroperoxide used as the acceptor substrate (Gunzler et al. 1974). The decrease in NADPH concentration was registered photometrically at $340 \mathrm{~nm}$. The GPx activity is expressed in $\mu \mathrm{mol} \mathrm{NADP}+/ \mathrm{min} / \mathrm{g}$ of tissue.

The serum activity of ALT and GLDH were estimated photometrically using the commercial kits (DiaSys Diagnostic System, Germany) according to the manufacturers' protocol.

\section{Electrophysiology and contractility measurements}

Electrophysiological and contractile properties of ventricular myocardium were determined using papillary muscles or trabeculae dissected form the right (RV) or left ventricle $(\mathrm{LV})$. The preparations were placed into an experimental chamber perfused with oxygenated Tyrode solution $\left(36^{\circ} \mathrm{C}\right)$ at a constant flow rate $(6-10 \mathrm{ml} / \mathrm{min})$. Tyrode solution 
contained (in mmol/1): $\mathrm{NaCl} 137, \mathrm{KCl} 4.5, \mathrm{MgCl}_{2}$ 1, $\mathrm{CaCl}_{2}$ 2, glucose 10, and HEPES 5; $\mathrm{pH}$ was adjusted to 7.4 with $\mathrm{NaOH}$. Then 30 minutes of stabilization period followed. When the steady state was reached, contraction force and membrane potential were measured with an isometric force transducer (model F30; Hugo Sachs Electronik - Harvard Apparatus, GmBH, March-Hugstetten, Germany) and glass microelectrodes filled with $3 \mathrm{M} \mathrm{KCl}$ (resistance $>20$ M $\Omega$; Microelectrode Puller P-1000, Sutter Instrument, CA, USA). Both signals were recorded using the National Instruments data-acquisition hardware and software (National Instruments Corporation, Austin, TX, USA) at stimulation frequencies 0.5, 1, 2, 3, and $5 \mathrm{~Hz}$ (Pulsemaster Multi-Channel Stimulator A300; World Precision Instruments, Inc., Sarasota, FL, USA).

For offline analysis of recorded signals a routine developed in MATLAB 2014b (MathWorks Inc., Natick, MA, USA, 2014) was applied. After determining of the resting membrane potential (RMP), the action potential duration was measured at the $50 \%$ and $90 \%$ levels of repolarization (APD50, APD90). The resting tension was taken as zero and then maximal amplitude of the contraction force (CFmax) was measured. Time course of the contraction force was characterized by three parameters: time-to-peak (TTP), time-to-50\%relaxation (R50), and time-to-90\%-relaxation (R90). All parameters were always measured in (at least) ten beats and the mean values were used for further analysis and comparisons. $R T-q P C R$

Hearts were rinsed with ice-cold saline, freed of connective tissue and fat and divided into the left atrium with the interatrial septum (LA), right atrium (RA) and ventricles, and frozen in liquid $\mathrm{N}_{2}$. All samples were homogenized by a ball mill (Mixer Mill MM300; Retsch GmbH, Haan, Germany) and the total RNA was isolated from LA and RA ( $n=5-7$ per group) using TRI reagent (Sigma Aldrich) according to the manufacturer's instructions. The purity and integrity of the RNA preparations were checked spectrophotometrically and by agarose gel electrophoresis. Contaminating DNA was destroyed with $1 \mathrm{U}$ DNase/ $\mu$ g total 
RNA (Invitrogen Corp., Carlsbad, CA, USA). First strand cDNA was synthetized from $2 \mu \mathrm{g}$ of total RNA in a $20 \mu \mathrm{l}$ total reaction mixture containing dithiothreitol, deoxynucleoside triphosphates, random primers and Superscript RNase H- Reverse Transcriptase IV (200 U/onset; Invitrogen Corp.) for $50 \mathrm{~min}$ at $42^{\circ} \mathrm{C}$. Quantitative real-time polymerase chain reaction (PCR) assay was performed in a Thermal Cycler (iCycler; Bio-Rad, Hercules, CA, USA) using primers and SYBR Green PCR kit (Bio-Rad). A negative control containing all reagents but no cDNA template was included in all runs. The primers were designed from sequences derived from the GenBank database using Primer to amplify the sequence corresponding to the published rat cDNA sequence for control genes ( $\beta$-actin, Ywhaz, CypA, Hmbs; see Table 1) and genes of interest (proANP, TH, DBH and ChAT; see Table 1). The PCR conditions were initial denaturation in one cycle of $15 \mathrm{~min}$ at $95^{\circ} \mathrm{C}$ followed by 45 cycles of $30 \mathrm{sec}$ at $95^{\circ} \mathrm{C}, 25 \mathrm{sec}$ at $59^{\circ} \mathrm{C}, 60^{\circ} \mathrm{C}$ or $62^{\circ} \mathrm{C}$, and $30 \mathrm{sec}$ at $72^{\circ} \mathrm{C}$. Although products emerged at a threshold of 20-36 cycles, a total of 45 cycles was run to reach saturation and to enable quantitative analysis. Each run was completed with a melting curve analysis in order to confirm the specificity of amplification and lack of primer dimers. After amplification, the samples were slowly heated from $65^{\circ} \mathrm{C}$ to $95^{\circ} \mathrm{C}$ with continuous reading of fluorescence to obtain a melting curve. Each pair of primers yielded a single peak in the melting curve and a single band of the expected size in agarose gel. Classical PCR reactions were first conducted to confirm the specificity of primers. The expected PCR products were utilized for production of standards, which were later used to establish the standard curves and assess efficiency of reaction as described previously (Slavikova et al. 2016).

Reactions for all samples were performed in triplicate and from these replicates, averages were calculated. Freely available computational program BestKeeper, excel-based tool using pair-wise correlations, was used for identifying the optimal normalization gene among a set of candidates reference genes as was in detail explained by the authors (Pfaffl et 
al. 2004). The expression level of the Ywhaz gene was used to normalize for differences in input cDNA in LA and $\beta$-actin in RA since these genes have been shown as the most stable genes in each atrium of all the tested reference genes in our experimental conditions. The quantification analysis of the data was performed by using the Optical System Software (BioRad). The relative differences in gene expression were calculated using quantitative cycle (Cq) values that were first normalized to those of the Ywhaz gene, the endogenous control in the same sample $(\Delta \mathrm{Cq}=\mathrm{Cq}$ target $-\mathrm{Cq}$ reference $)$, and then relative to a $\Delta \mathrm{Cq}$ value of control animals by the $2^{-\Delta \Delta \mathrm{Cq}}$ method as described previously (Chottova Dvorakova et al. 2005). Values obtained for group TAA were compared with those for $\mathrm{CO}$, and BDL with $\mathrm{CO}$, respectively. The PCR products were separated by electrophoresis on a $2.0 \%$ Tris-acetateEDTA agarose gel. Controls run by omission of the RT step or by omission of template were negative.

Statistical Analysis

All data are expressed as the mean \pm standard error of the mean (SEM) and statistical analysis was performed using Mann-Whitney test. Values of $p<0.05$ were considered statistically significant. The analysis was performed using the software package STATISTICA Cz, version 7 (StatSoft CR, Prague, Czech Republic).

\section{Results}

The initial body weights were similar in all groups. TAA treatment significantly decreased the body weight compared to the control group, whereas BDL did not affect the body weight significantly. Mean values of body weights together with the normalized liver and heart weights from all experimental groups are shown in Figure 1. Significant enlargement of the liver observed in TAA and BDL groups is compatible with liver cirrhosis. No differences were detected between all experimental groups for the cardiac mass index. 


\section{Histopathological evaluation}

To confirm development of liver cirrhosis in rats after TAA or BDL treatment, liver sections from rats of all experimental groups were evaluated by light microscopy. Liver rat specimens from $\mathrm{CO}$ showed normal liver architecture with no significant changes in hepatocytes and portal tracts. Very rarely, some hepatocytes (close to central vein) showed pale, clear staining cytoplasm, portal triad had normal appearance (Fig. 2A, B). Liver specimens taken from rats with TAA application manifested proliferation of collagenous connective tissue together with an inflammatory infiltration and a sign of cholestasis, the bile was visible inside and outside defined structures. Hepatocytes showing condensation of cytoplasm and fragmentation of nuclei were present at the periphery of liver lobules (Fig. 2C, D). In specimens of rats, which underwent surgical procedure BDL, there were visible some features associated with the bile cholestasis as proliferation and dilatation of bile ducts with ductular reaction with signs of hepatocytes degeneration. In some specimens it was possible to detect conspicuous areas of a necrosis and degeneration of hepatocytes with inflammatory cell margin (Fig. 2E, F). These areas of bile infarcts were very probably due to leakage of the bile (as a result of surgical procedure).

PSR staining was carried out to evaluate the extent of liver fibrosis, when it allowed visualizing green - thin fibers (type III collagen or immature thin type fiber - collagen I) and orange or red thick type I fibers. In $\mathrm{CO}$ - very small amounts of collagen of both types I and III were visible (Fig. 3A). Liver specimens from rats with TAA application manifested the most prominent changes: accumulation of collagen type I (thick fibers) especially in areas of portal triad. Hepatic lobules (morphological units) were separated by collagen of both types: I and III (Fig. 3B). Specimens from rats with BDL procedure displayed accumulation of collagen type I predominantly in areas of central vein and portal triad, but the separation of liver lobules by collagen was not documented (Fig. 3C). 


\section{Biochemical evaluation}

TAA administration significantly increased serum AST and GLDH activities. Lipid peroxidation expressed as MDA concentration was significantly increased and GPx activity was significantly decreased in the liver, but no change was seen in the cardiac tissue after TAA administration.

BDL significantly increased activities of both ALT and GLDH. The activity of GPx and the concentration of MDA were significantly decreased in the liver of operated animals. In the cardiac tissue, the activity of GPx was significantly decreased and MDA concentration was significantly increased in operated animals (Tab. 2).

\section{Electrophysiology and contractility measurements}

As shown in Figure 4, action potentials and contraction force traces were similar in all studied groups (CO, TAA, and BDL) at stimulation frequency of $1 \mathrm{~Hz}$ in the LV. Also at the other stimulation frequencies used $(1,2,3$, and $5 \mathrm{~Hz})$, there were no significant differences detected in any of the measured action potentials (RMP, APD50, and APD90) and/or contraction force parameters (CFmax, TTP, R50, and R90) in both LV and RV.

\section{Gene expression in heart tissue}

To investigate the effect of TAA and BDL treatment on natriuretic peptides, expression of mRNA for proANP was analyzed in LA and RA using real-time RT-PCR. In TAA treatment group, there was a trend to down-regulation of the proANP gene expression in RA, but it did not reach statistical significance. In LA, no difference in proANP expression was noticed between all experimental groups (Fig. 5).

Effects of liver cirrhosis on intracardiac nervous system were evaluated in both atria through measurements of expression of genes for enzymes responsible for synthesis of classical neurotransmitters, TH, DBH and ChAT. In the LA, expression of mRNA for TH and DBH was significantly lower in BDL group compared to control group, whereas there were 
no significant differences between TAA and control groups. In the RA, expression of mRNA for $\mathrm{TH}$ and $\mathrm{DBH}$ was not significantly different in all experimental groups (Fig. 6). No significant differences between experimental groups were found also for expression of ChAT mRNA in the LA, while in the RA expression level of the gene was too low for quantitative analysis (Fig. 7). Subsequent analysis of PCR products by gel electrophoresis revealed presence of band of expected size proving occurrence of ChAT mRNA in samples.

\section{Discussion}

Cirrhotic cardiomyopathy is cardiac dysfunction present in patients with cirrhosis. Clinical observations indicate that etiology of cirrhosis is not determinative factor for presence or absence of cirrhotic cardiomyopathy (Moller and Henriksen 2010). The existence of a systemic circulatory disorder in liver cirrhosis was described more than 60 years ago (Kowalski and Abelmann 1953), nevertheless the underlying mechanisms involved in pathogenesis are still poorly understood and treatment of cirrhotic cardiomyopathy is limited, partially due to the lack of satisfactory animal models. There are many experimental models to induce hepatic fibrosis (Bhakuni et al. 2016). However, none of them systematically evaluates similarities and differences between animal models of cirrhotic cardiomyopathy and clinical picture of the disease. The duration of the experiment and severity of induced liver fibrosis are also very important, since correlation between severity of the liver disease and the presence of cardiac disturbances has been documented in patients (Bernardi et al. 1998; Moller et al. 2007). Cirrhotic cardiomyopathy occurs in more than 50\% of patients with endstage liver diseases (Torregrosa et al. 2005), which leads to a question what portion of animals with induced cirrhosis finally develops cardiomyopathy.

The two well established and very frequently used experimental models of liver cirrhosis are the administration of TAA, and the common bile duct ligation (Bhakuni et al. 
2016). Both of them induce liver fibrosis if the appropriate protocol is used (Marques et al. 2012; Wallace et al. 2015). The administration of TAA causes oxidative stress, glutathione depletion and thus injury affecting hepatocytes and cholangiocytes, which finally leads to liver fibrosis and cirrhosis (Wallace et al. 2015). BDL induces progressive changes in the hepatic architecture, namely inflammation and fibrosis (Mohamed et al. 2015). These findings correspond with results of our histopathological evaluations. Enhanced lipid peroxidation is one of the basic mechanisms involved in oxidative stress-induced cell damage and it has been shown to be involved in lesion of different tissues including liver and nerve tissue (Nordmann et al. 1990). Liver MDA concentrations were significantly increased in TAA animals but decreased in operated animals. It has been previously shown by Mohamed with co-workers, that the level of MDA in liver after BDL is time-dependent. It reaches the peak value 4 weeks after the ligation, then gradually decreases and reaches the values of sham-operated rats in 8 10 weeks. The authors of the study explain the decline by possible consumption of MDA in cross-linking of collagen (Mohamed et al. 2015). Such mechanism may be involved in decreased MDA levels in our experiment.

In the intact heart, MDA concentration was approximately two times lower than in liver of control animals, which corresponds with literature showing different levels of MDA in various tissues (Bludovska et al.2013; Mustafa et al 2013). Cholestatic liver disease is associated with increased lipid peroxidation markers (Ljubuncic et al. 2000) as well as chronic TAA treatment (Amirtharaj et al. 2017). BDL caused increase of the MDA in hearts, while TAA treatment did not induce any change of MDA there. Significant increase in concentration of MDA and significant decrease in GPx activity in hearts of operated animals could be results of systemic oxidative stress, a known consequence of cholestatic liver disease (Assimakopoulos et al. 2008; Ljubuncic et al. 2000). An accumulation of bile salts contributes to oxidative stress (Pastor et al. 1997). Ma with co-workers showed that bile acid levels in 
BDL rats were significantly higher than in TAA treated rats (Ma et al 1999). This could explain the difference in MDA production in heart between the TAA and BDL animals in the present study. An unsolved question remains whether MDA production could be influenced by the direct effect of TAA on cardiac tissue. Amirtharaj with co-workers (Amirtharaj et al. 2017) showed that permanent application of TAA caused over production of MDA in the rat heart, which culminated 12 weeks after the beginning of TAA treatment. In our experiment, application of TAA was stopped 8 weeks before sacrifice of experimental animals and, although it has been demonstrated previously, that chronic application of TAA does not cause any histological changes in the heart (Amirtharaj et al. 2017), the absence of higher MDA level in the heart of TAA so long after the treatment discontinuation could indicate some direct effect of TAA on the level of lipid peroxidation in the hearts of rats continuously treated with TAA.

All measurements of electrophysiological and contractile parameters were performed in vitro, thus minimizing possible influences of autonomic nervous system present in vivo. Furthermore, preparations of limited size (papillary muscles) from left ventricle were used. With regard to the considerable heterogeneity of the heart tissue, it is possible that some effects of hepatic failure were missed. However, in another study of a similar cirrhosis rat model no significant changes of overall left ventricular contractility measured in isolated heart were found (Ceolotto et al. 2008) arguing against heterogeneous hepatic-failure induced cardiac remodeling.

The determination of natriuretic peptides plays an important role in the diagnosis of cirrhotic cardiomyopathy. ANP is regarded as a marker of volume overload and is found to be increased in decompensated cirrhosis when intracardiac volume and pressure conditions are altered, typically in patients with increased intravascular volume and LV hypertrophy (Moller and Henriksen 2010; Tsang et al. 2002). ANP plasma levels are elevated in patients with 
cirrhosis and ascites, and also some pre-ascitic patients (Ruiz-del-Arbol and Serradilla 2015). In order to evaluate, whether such conditions might come from an increased synthesis of ANP in the heart, expression of proANP mRNA was measured in LA and RA of all experimental animals. Similar levels of the expression in all experimental groups in our experiment could be explained by the absence of LV hypertrophy, which is clear from relative and absolute (data not shown) heart weights that are rather similar in all experimental groups. This is also in agreement with the results of Amirtharaj (Amirtharaj et al. 2016) and Ma (Ma et al. 1996), whose findings exclude presence of cardiac hypertrophy in TAA and BDL rats. Unchanged expression of the gene for proANP also suggests that our experimental protocols probably did not induce a rise of intravascular volume in experimental animals.

Cardiac dysfunction is considered to be multifactorial in chronic liver diseases. Oxidative stress has been suggested to be one of such factors (Yang et al. 2010). Oxidative stress is the result of changes in the balance between reactive oxygen species (ROS) and antioxidant capacity in favor of oxidants or against antioxidant capacity. ROS cause cellular dysfunction, protein and lipid peroxidation, and DNA damage and can lead to irreversible cell damage and death (Khurana et al. 2013). In the heart, ROS can directly impair contractile function, activate a broad variety of hypertrophy signaling kinases, stimulate cardiac fibroblast proliferation and activate matrix metalloproteinases, which can finally lead to development and progression of maladaptive myocardial remodeling and failure (Tsutsui et al. 2011). Alterations of the ANS functions including reduced heart rate variability together with autonomic dysfunction in both sympathetic and parasympathetic components of heart innervation has been reported in patients with chronic liver disease (Dumcke and Moller 2008). In order to observe effects of chronic cirrhosis on intracardiac neurons, mRNAs for TH, DBH, and ChAT, were studied in LA. In the rat heart, LA and atrial wall above interatrial septum are the main sites of nerve cell bodies of intracardiac nervous system. RA contains 
lower amount of neurons and ventricles does not include them (Pardini et al. 1987). This corresponds with our results showing that levels of expression of genes for DBH and ChAT were higher in the LA (data not shown). Intracardiac ganglia contain predominantly cholinergic neurons, but to a much lesser extent, also catecholaminergic neurons and small intensely fluorescent (SIF) cells, which represent the main production source of catecholamines (CA) in the heart (Slavikova et al. 2003). SIF cells are involved in vagal local afferent reflexes, so they play a modulatory role in controlling the heart (Cheng and Powley 2000). Reduced expression of enzymes responsible for CA production could underlie limited ability of heart to correspond to physical or pharmacological stress, manifestations described in patients with cirrhotic cardiomyopathy (Ruiz-del-Arbol and Serradilla 2015). Oxidative stress demonstrated in the heart of BDL animals in this study could be responsible for reduction of $\mathrm{TH}$ expression, since such regulatory mechanism has been demonstrated in PC12 cells (Kroll et al. 1998).

There is a limitation to be acknowledged in this study. Quantification of ANP, TH and DBH peptides would make the data more convincing.

In conclusion, results of this study for the first time document different effect of TAA and BDL treatment on the heart lipid peroxidation and intracardiac innervation. BDL procedure is responsible for lowering of cardiac CA production in the heart, which could be caused by higher level of oxidative stress in the heart and would lead to impaired nervous control in the heart.

\section{Acknowledgements}

We gratefully thank to Jaroslava Lodrova, Monika Novakova and Marketa Slajerova, Master of Engineering, for excellent technical and laboratory support and to Milan Stengl, Ph.D., for critical reading the manuscript and helpful discussion. This work was supported by 
the Charles University Research Fund (project number P36), by the National Sustainability

Program I (NPU I) Nr. LO1503 provided by the Ministry of Education Youth and Sports of the Czech Republic, and by the Specific Student Research Project Nr. 260281/2016 of the Charles University, Prague.

\section{References}

Amirtharaj, G.J., Natarajan, S.K., Pulimood, A., Balasubramanian, K.A., Venkatraman, A., and Ramachandran, A. 2017. Role of Oxygen Free Radicals, Nitric Oxide and Mitochondria in Mediating Cardiac Alterations During Liver Cirrhosis Induced by Thioacetamide. Cardiovasc. Toxicol. 17(2): 175-184. doi: 10.1007/s12012-016-9371-1. PMID: 27131982.

Assimakopoulos, S.F., Mavrakis, A.G., Grintzalis, K., Papapostolou, I., Zervoudakis, G., Konstantinou, D., et al. 2008. Superoxide radical formation in diverse organs of rats with experimentally induced obstructive jaundice. Redox. Rep. 13(4): 179-184. doi: 10.1179/135100008x308902. PMID: 18647488.

Bernardi, M., Calandra, S., Colantoni, A., Trevisani, F., Raimondo, M.L., Sica, G., et al. 1998. Q-T interval prolongation in cirrhosis: prevalence, relationship with severity, and etiology of the disease and possible pathogenetic factors. Hepatology, 27(1): 28-34. doi: 10.1002/hep.510270106. PMID: 9425913.

Bhakuni, G.S., Bedi, O., Bariwal, J., Deshmukh, R., and Kumar, P. 2016. Animal models of hepatotoxicity. Inflamm. Res. 65(1): 13-24. doi: 10.1007/s00011-015-0883-0. PMID: 26427493.

Bludovska, M., Mistrova, E., Kotyzova, D., and Chottova-Dvorakova, M. 2013. The influence of chronic administration of thioacetamide on levels of ALT, AST and GLDH in serum and markers of oxidative stress in the liver and kidneys of female Wistar rats. Biomedical Papers-Olomouc, 157: S65-S69.

Cheng, Z., and Powley, T.L. 2000. Nucleus ambiguus projections to cardiac ganglia of rat atria: an anterograde tracing study. J. Comp. Neurol. 424(4): 588-606. PMID: 10931483.

Chottova Dvorakova, M., Kuncova, J., Pfeil, U., McGregor, G.P., Sviglerova, J., Slavikova, J., et al. 2005. Cardiomyopathy in streptozotocin-induced diabetes involves intra-axonal accumulation of calcitonin gene-related peptide and altered expression of its receptor in rats. Neuroscience, 134(1): 51-58. doi: 10.1016/j.neuroscience.2005.03.058. PMID: 15951122.

Ceolotto, G., Papparella, I., Sticca, A., Bova, S., Cavalli, M., Cargnelli, G., et al. 2008. An Abnormal Gene Expression of the Beta-Adrenergic System Contributes to the Pathogenesis of Cardiomyopathy in Cirrhotic Rats. Hepatology, 48 (6): 1913-1923. doi:10.1002/hep.22533. PMID: 19003918.

Dashti, H., Jeppsson, B., Hagerstrand, I., Hultberg, B., Srinivas, U., Abdulla, M., et al. 1989. Thioacetamide- and carbon tetrachloride-induced liver cirrhosis. Eur. Surg. Res. 21(2): 83-91. PMID: 2767088.

Dumcke, C.W., and Moller, S. 2008. Autonomic dysfunction in cirrhosis and portal hypertension. Scand. J. Clin. Lab. Invest. 68(6): 437-447. doi: 10.1080/00365510701813096. PMID: 18609092.

Gunzler, W.A., Kremers, H., and Flohe, L. 1974. An improved coupled test procedure for glutathione peroxidase (EC 1-11-1-9-) in blood. Z. Klin. Chem. Klin. Biochem. 12(10): 444-448. PMID: 4154542.

Jaue, D.N., Ma, Z., and Lee, S.S. 1997. Cardiac muscarinic receptor function in rats with cirrhotic cardiomyopathy. Hepatology, 25(6): 1361-1365. doi: 10.1002/hep.510250610. PMID: 9185753. 
Karagiannakis, D.S., Papatheodoridis, G., and Vlachogiannakos, J. 2015. Recent advances in cirrhotic cardiomyopathy. Dig. Dis. Sci. 60(5): 1141-1151. doi: 10.1007/s10620-014-3432-8. PMID: 25404411.

Khurana, S., Piche, M., Hollingsworth, A., Venkataraman, K., and Tai, T.C. 2013. Oxidative stress and cardiovascular health: therapeutic potential of polyphenols. Can. J. Physiol. Pharmacol. 91(3): 198-212. doi: 10.1139/cjpp-2012-0252. PMID: 23537433.

Kowalski, H.J., and Abelmann, W.H. 1953. The cardiac output at rest in Laennec's cirrhosis. J. Clin. Invest. 32(10): 1025-1033. doi: 10.1172/jci102813. PMID: 13096569.

Kroll, S.L., and Czyzyk-Krzeska, M.F. 1998. Role of H2O2 and heme-containing $\mathrm{O} 2$ sensors in hypoxic regulation of tyrosine hydroxylase gene expression. Am. J. Physiol. 274(1): C167-C174. PMID: 9458725

Liu, H., Gaskari, S.A., and Lee, S.S. 2006. Cardiac and vascular changes in cirrhosis: pathogenic mechanisms. World J. Gastroenterol. 12(6): 837-842. PMID: 16521209.

Ljubuncic, P., Tanne, Z., and Bomzon, A. 2000. Evidence of a systemic phenomenon for oxidative stress in cholestatic liver disease. Gut, 47(5): 710-716. PMID: 11034590.

Low, T.Y., Leow, C.K., Salto-Tellez, M., and Chung, M.C. 2004. A proteomic analysis of thioacetamideinduced hepatotoxicity and cirrhosis in rat livers. Proteomics, 4(12): 3960-3974. doi: 10.1002/pmic.200400852. PMID: 15526343.

Ma, Z., Miyamoto, A., and Lee, S.S. 1996. Role of altered beta-adrenoceptor signal transduction in the pathogenesis of cirrhotic cardiomyopathy in rats. Gastroenterology, 110(4): 1191-1198. PMID: 8613009.

Ma, Z., Zhang, Y., Huet, P.M., and Lee, S.S. 1999. Differential effects of jaundice and cirrhosis on betaadrenoceptor signaling in three rat models of cirrhotic cardiomyopathy. J. Hepatol. 30(3): 48591. PMID: 10190733

Marques, T.G., Chaib, E., da Fonseca, J.H., Lourenco, A.C., Silva, F.D., Ribeiro, M.A., Jr., et al. 2012. Review of experimental models for inducing hepatic cirrhosis by bile duct ligation and carbon tetrachloride injection. Acta Cir. Bras. 27(8): 589-594. PMID: 22850713.

Mihara, M., and Uchiyama, M. 1978. Determination of malonaldehyde precursor in tissues by thiobarbituric acid test. Anal. Biochem. 86(1): 271-278. PMID: 655387.

Mohamed, H.E., Elswefy, S.E., Rashed, L.A., Younis, N.N., Shaheen, M.A., and Ghanim, A.M.H. 2015. Cholestatic liver fibrosis in a rat model of bile duct ligation: Evaluating biochemical versus histopathological changes. Int. J. Pharm. Pharm. Sci. 7(6): 349-354.

Moller, S., and Henriksen, J.H. 2010. Cirrhotic cardiomyopathy. J. Hepatol. 53(1): 179-190. doi: 10.1016/j.jhep.2010.02.023. PMID: 20462649.

Moller, S., Iversen, J.S., Henriksen, J.H., and Bendtsen, F. 2007. Reduced baroreflex sensitivity in alcoholic cirrhosis: relations to hemodynamics and humoral systems. Am. J. Physiol. Heart. Circ. Physiol. 292(6): H2966-2972. doi: 10.1152/ajpheart.01227.2006. PMID: 17293491.

Mustafa, H.N., El Awdan, S.A., Hegazy, G.A. 2013. Protective role of antioxidants on Thioacetamideinduced acute hepatic encephalopathy: biochemical and ultrastructural study. Tissue Cell, 45(5): 350-362. doi: 10.1016/j.tice.2013.06.001. PMID: 23876406.

Natarajan, S.K., Thomas, S., Ramamoorthy, P., Basivireddy, J., Pulimood, A.B., Ramachandran, A., et al. 2006. Oxidative stress in the development of liver cirrhosis: a comparison of two different experimental models. J. Gastroenterol. Hepatol. 21(6): 947-957. doi: 10.1111/j.14401746.2006.04231.x. PMID: 16724977.

Nordmann, R., Ribiere, C., and Rouach, H. 1990. Ethanol-induced lipid peroxidation and oxidative stress in extrahepatic tissues. Alcohol Alcohol. 25(2-3): 231-237. PMID: 2198038.

Pardini, B.J., Patel, K.P., Schmid, P.G., and Lund, D.D. 1987. Location, distribution and projections of intracardiac ganglion cells in the rat. J. Auton. Nerv. Syst. 20(2): 91-101. PMID: 3668165.

Pastor, A., Collado, P.S., Almar, M., and Gonzalez-Gallego, J. 1997. Antioxidant enzyme status in biliary obstructed rats: effects of N-acetylcysteine. J. Hepatol. 27(2): 363-370. PMID: 9288612. 
Pereira, R.M., dos Santos, R.A., Oliveira, E.A., Leite, V.H., Dias, F.L., Rezende, A.S., et al. 2008. Development of hepatorenal syndrome in bile duct ligated rats. World J. Gastroenterol. 14(28): 4505-4511. PMID: 18680230.

Pfaffl, M.W., Tichopad, A., Prgomet, C., and Neuvians, T.P. 2004. Determination of stable housekeeping genes, differentially regulated target genes and sample integrity: BestKeeper-Excel-based tool using pair-wise correlations. Biotechnol Lett 26(6): 509-515. PMID: 15127793.

Rich, L., and Whittaker P. 2005. Collagen and Picrosirius Red staining: a polarized light assessment of fibrillar hue and spatial distribution. Braz. J. Morphol. Sci. 22(2): 97-104.

Ruiz-del-Arbol, L., and Serradilla, R. 2015. Cirrhotic cardiomyopathy. World J. Gastroenterol. 21(41): 11502-11521. doi: 10.3748/wjg.v21.i41.11502. PMID: 26556983.

Slavikova, J., Kuncova, J., Reischig, J., and Dvorakova, M. 2003. Catecholaminergic neurons in the rat intrinsic cardiac nervous system. Neurochem. Res. 28(3-4): 593-598. PMID: 12675149.

Slavikova, J., Mistrova, E., Klenerova, V., Kruzliak, P., Caprnda, M., Hynie, S., et al. 2016. Effects of immobilizations stress with or without water immersion on the expression of atrial natriuretic peptide in the hearts of two rat strains. Am. J. Transl. Res. 8(7): 3148-3158. PMID: 27508036.

Torregrosa, M., Aguade, S., Dos, L., Segura, R., Gonzalez, A., Evangelista, A., et al. 2005. Cardiac alterations in cirrhosis: reversibility after liver transplantation. J. Hepatol. 42(1): 68-74. doi: 10.1016/j.jhep.2004.09.008. PMID: 15629509.

Tsang, T.S., Barnes, M.E., Gersh, B.J., Bailey, K.R., and Seward, J.B. 2002. Left atrial volume as a morphophysiologic expression of left ventricular diastolic dysfunction and relation to cardiovascular risk burden. Am. J. Cardiol. 90(12): 1284-1289. PMID: 12480035.

Tsutsui, H., Kinugawa, S., and Matsushima, S. 2011. Oxidative stress and heart failure. Am. J. Physiol. Heart Circ. Physiol. 301(6): H2181-2190. doi: 10.1152/ajpheart.00554.2011. PMID: 21949114

Wallace, M.C., Hamesch, K., Lunova, M., Kim, Y., Weiskirchen, R., Strnad, P., et al. 2015. Standard operating procedures in experimental liver research: thioacetamide model in mice and rats. Lab. Anim. 49(1 Suppl): 21-29. doi: 10.1177/0023677215573040. PMID: 25835735.

Yang, Y.Y., Liu, H., Nam, S.W., Kunos, G., and Lee, S.S. 2010. Mechanisms of TNFalpha-induced cardiac dysfunction in cholestatic bile duct-ligated mice: interaction between TNFalpha and endocannabinoids. J. Hepatol. 53(2): 298-306. doi: 10.1016/j.jhep.2010.03.011. PMID: 20626112. 
Table 1: Sequences of used primer pairs.

\begin{tabular}{|c|c|c|c|c|c|}
\hline Amplicon & Range & & Primer sequence & $\begin{array}{l}\text { Product } \\
\text { length }\end{array}$ & $\begin{array}{c}\text { Genebank } \\
\text { acc. No. }\end{array}$ \\
\hline \multirow[t]{2}{*}{$\overline{\beta \beta \text {-actin }}$} & \multirow[t]{2}{*}{$873-969$} & for & ttccttcctgggtatggaatc & \multirow[t]{2}{*}{$97 \mathrm{bp}$} & \multirow[t]{2}{*}{ NM_31144 } \\
\hline & & rev & gttggcatagaggtctttacgg & & \\
\hline \multirow[t]{2}{*}{ Hmbs } & \multirow[t]{2}{*}{$908-1057$} & for & ggctgtagcgtgccagtagcag & \multirow[t]{2}{*}{$150 \mathrm{bp}$} & \multirow[t]{2}{*}{ NM_013168.2 } \\
\hline & & rev & tggaccatcttcttgctgaaca & & \\
\hline \multirow[t]{2}{*}{ CypA } & \multirow[t]{2}{*}{$381-507$} & for & tatctgcactgccaagactgagtg & \multirow[t]{2}{*}{$126 \mathrm{bp}$} & \multirow[t]{2}{*}{$\overline{\text { NM_017101.1 }}$} \\
\hline & & rev & cttcttgctggtcttgccattcc & & \\
\hline \multirow[t]{2}{*}{ Ywhaz } & \multirow[t]{2}{*}{$539-671$} & for & gatgaagccattgctgaacttg & \multirow[t]{2}{*}{$133 \mathrm{bp}$} & \multirow[t]{2}{*}{ NM_013011.3 } \\
\hline & & rev & ctccegcttctgcttcgtctcc & & \\
\hline \multirow[t]{2}{*}{ proANP } & \multirow[t]{2}{*}{$172-242$} & for & caacacagatctgatggatttca & \multirow[t]{2}{*}{$71 \mathrm{bp}$} & \multirow[t]{2}{*}{ NM_012612.2 } \\
\hline & & rev & cctcatcttctaccggcatc & & \\
\hline \multirow[t]{2}{*}{ TH } & \multirow[t]{2}{*}{$949-1168$} & for & cttctctgaccaggtgtatcg & \multirow[t]{2}{*}{$220 \mathrm{bp}$} & \multirow[t]{2}{*}{ L22651.1 } \\
\hline & & rev & ctctcggtagcccacgtacc & & \\
\hline \multirow[t]{2}{*}{$\overline{\mathrm{DBH}}$} & \multirow[t]{2}{*}{$1218-1321$} & for & atctggaatccgcatctttg & \multirow[t]{2}{*}{104 bp } & \multirow[t]{2}{*}{ NM_013158.2 } \\
\hline & & rev & tgttcaccacttccctctgt & & \\
\hline \multirow[t]{2}{*}{ ChAT } & \multirow[t]{2}{*}{$1175-1313$} & for & agctcagtgacacccacagg & \multirow[t]{2}{*}{$139 \mathrm{bp}$} & \multirow[t]{2}{*}{ XM_224626 } \\
\hline & & rev & gaatgctcacacaccacacc & & \\
\hline
\end{tabular}

Table 2: Serum, liver and heart biochemistry tests.

\begin{tabular}{lccc}
\hline Serum & CO & TAA & BDL \\
\hline ALT (U/L) & $45.4 \pm 2.59$ & $55.5 \pm 3.81$ & $255.4 \pm 185.68^{* * *}$ \\
GLDH (U/L) & $15.9 \pm 1.19$ & $36.36 \pm 5.85^{* *}$ & $167 \pm 113.06^{* * *}$ \\
\hline Liver & CO & TAA & BDL \\
\hline LP (MDA nmol/g) & $74.29 \pm 2.62$ & $107.45 \pm 3.72^{* * *}$ & $56.78 \pm 5.36^{*}$ \\
GPx (U/g) & $37.29 \pm 1.66$ & $23.49 \pm 0.68^{* * *}$ & $22.6 \pm 6.47^{*}$ \\
\hline Heart & & & BDL \\
\hline LP (MDA nmol/g) & $36.31 \pm 1.13$ & $39.13 \pm 0.92$ & $47.04 \pm 5.45^{*}$ \\
GPx (U/g) & $7.78 \pm 0.17$ & $7.51 \pm 0.31$ & $6.9 \pm 0.26^{*}$
\end{tabular}

Note: Values represent means $\pm \operatorname{SEM}\left(n=5-10\right.$ in each group); ${ }^{*} p<0.05 ;{ }^{* *} p<0.01 ; * * * p<$ 0.001 versus control animals $(\mathrm{CO})$. 


\section{Figure legend}

Figure 1: Body weights and cardiac and liver indexes of control, TAA and BDL animals. Values are expressed as mean \pm SEM. A: Body weights. B: Normalized heart weights expressed in $\mathrm{g}$ of organ wet weight/100 $\mathrm{g}$ of body weight. C: Normalized liver weights expressed in $\mathrm{g}$ organ wet weight/100 $\mathrm{g}$ of body weight.

Figure 2: A: Liver of rat from control group (CO). Hepatic lobule with central vein, radially arranged liver cords and sinusoids, without conspicuous changes, only solitary hepatocytes with lipid droplets are visible (HE staining; scale bar $50 \mu \mathrm{m}$ ). B: Liver of CO rat. Portal triad with interlobular artery, vein and bile duct in the middle, and sinusoids (HE staining; scale bar $50 \mu \mathrm{m}) . \mathbf{C}$ : Liver of rat with thioacetamide application (TAA). Changed hepatocytes showing condensation of cytoplasm and fragmentation of nuclei (arrows), which both are sign of apoptosis, are present at the periphery of liver lobules (HE staining; scale bar $50 \mu \mathrm{m}$ ). D: Liver of TAA rat. Proliferation of collagenous connective tissue and presence of inflammatory cells is noticeable (arrow) and sign of cholestasis in the form of bile (asterisk) within (and outside) bile canaliculi and macrophages, in portal area especially (HE staining; scale bar $50 \mu \mathrm{m})$. E: Liver of rat underwent bile duct ligation (BDL). A focus of inflammatory cells consisting of neutrophils and macrophages (arrow), which surround an area with sign of necrosis and degeneration of hepatocytes with borderline from hepatocytes showing condensation of cytoplasm and fragmentation (asterisk; HE staining; scale bar 100 $\mu \mathrm{m})$. F: Liver of BDL rat. Proliferation and dilatation of bile ducts with ductular reaction is visible (arrow). Hepatocytes with condensation of cytoplasm and fragmentation of nuclei are documented (thick arrow) as well as presence of bile as sign of cholestasis (asterisk) among structures (HE staining; scale bar $50 \mu \mathrm{m}$ ). 
Figure 3: Picrosirius red-stained (PSR) liver sections. A: Liver of rat from control group (CO). Original image viewed with circularly polarized light. Small amount of collagen I and III is visible closely to central vein and portal triad (scale bar $200 \mu \mathrm{m}$ ). B: Liver of TAA rat. PSR- stained slide demonstrates changes in liver tissue: conspicuous feature is content of collagen type I (thick fibers) especially in areas of portal triad. Hepatic lobules (morphological units) are separated by collagen of both types I and III (thin fibers or immature I type fibers; scale bar $200 \mu \mathrm{m}$ ). C: Liver of BDL rat. PSR-stained section shows accumulation of collagen, predominantly type I (thick fibers) in areas with central vein and portal triad. Separation of liver lobules is not visible (scale bar $200 \mu \mathrm{m}$ ).

Figure 4: A: Representative action potentials recorded in the preparations from the left ventricle at stimulation frequency of $1 \mathrm{~Hz}$ in control group (CO), group treated with thioacetamide (TAA) and group with bile duct ligation (BDL). B: Representative contraction force traces recorded in the preparations from the left ventricle at stimulation frequency of 1 $\mathrm{Hz}$ in control group (CO), group treated with thioacetamide (TAA) and group with bile duct ligation (BDL).

Figure 5: Real time RT-PCR of the proANP gene in the left (LA) and right atria (RA) of control group (CO), group treated with thioacetamide (TAA) and group with bile duct ligation (BDL). The relative expression was achieved by normalizing expression of the proANP gene to reference gene by the $\Delta \Delta \mathrm{Cq}$ method. Values of $\mathrm{CO}$ in the appropriate heart compartments were used as comparators and settled as 1 . Error bars represent the standard error of mean ( $n$ $=5-7)$. 
Figure 6: Real time RT-PCR of TH and DBH genes in the left (LA) and right atria (RA) of control group $(\mathrm{CO})$, group treated with thioacetamide (TAA) and group with bile duct ligation (BDL). The relative expression was achieved by normalizing the expression of the gene of interest to reference gene by the $\Delta \Delta \mathrm{Cq}$ method. Values of $\mathrm{CO}$ were used as comparators and settled as 1 . Error bars represent the standard error of mean $\left(n=5-7 ;{ }^{*} p<0.05\right)$.

Figure 7: Real time RT-PCR of ChAT gene in the left atrium (LA) of control group (CO), group treated with thioacetamide (TAA) and group with bile duct ligation (BDL). The relative expression was achieved by normalizing the expression of the gene of interest to reference gene by the $\Delta \Delta \mathrm{Cq}$ method. Values of $\mathrm{CO}$ were used as comparators and settled as 1 . Error bars represent the standard error of mean $(n=5-7)$. 
Fig. 1

A

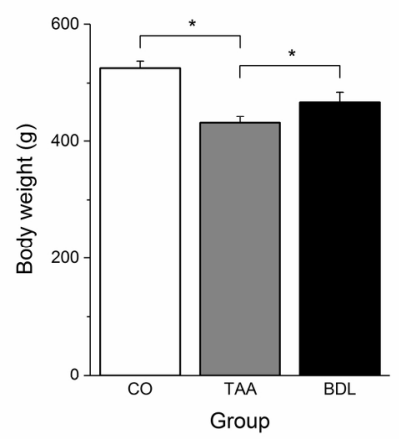

B

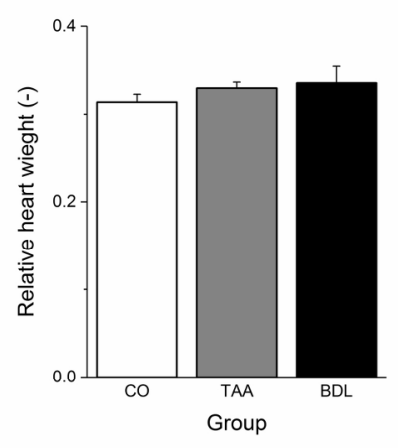

C

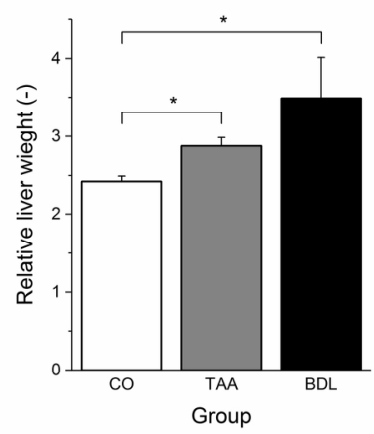

$90 \times 45 \mathrm{~mm}(600 \times 600 \mathrm{DPI})$ 
Fig. 2

$\mathrm{CO}$
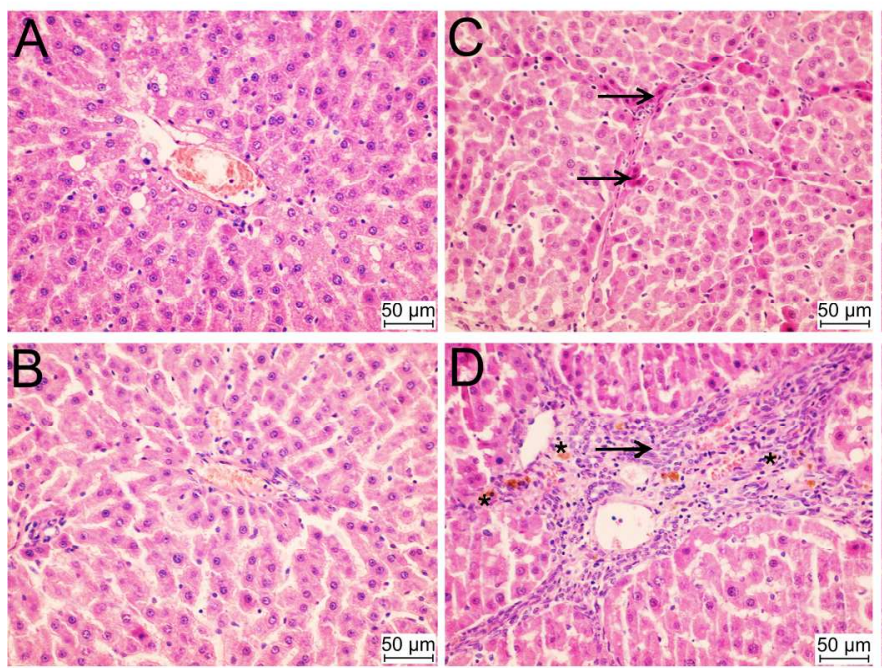

TAA

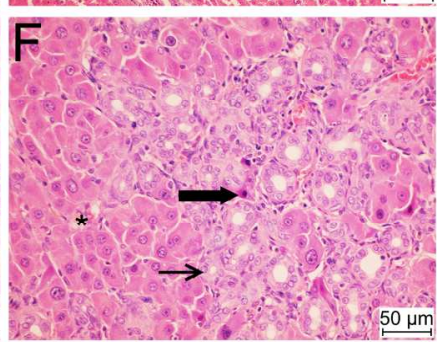

$181 \times 119 \mathrm{~mm}(300 \times 300 \mathrm{DPI})$ 
Fig. 3

CO

TAA

BDL

A

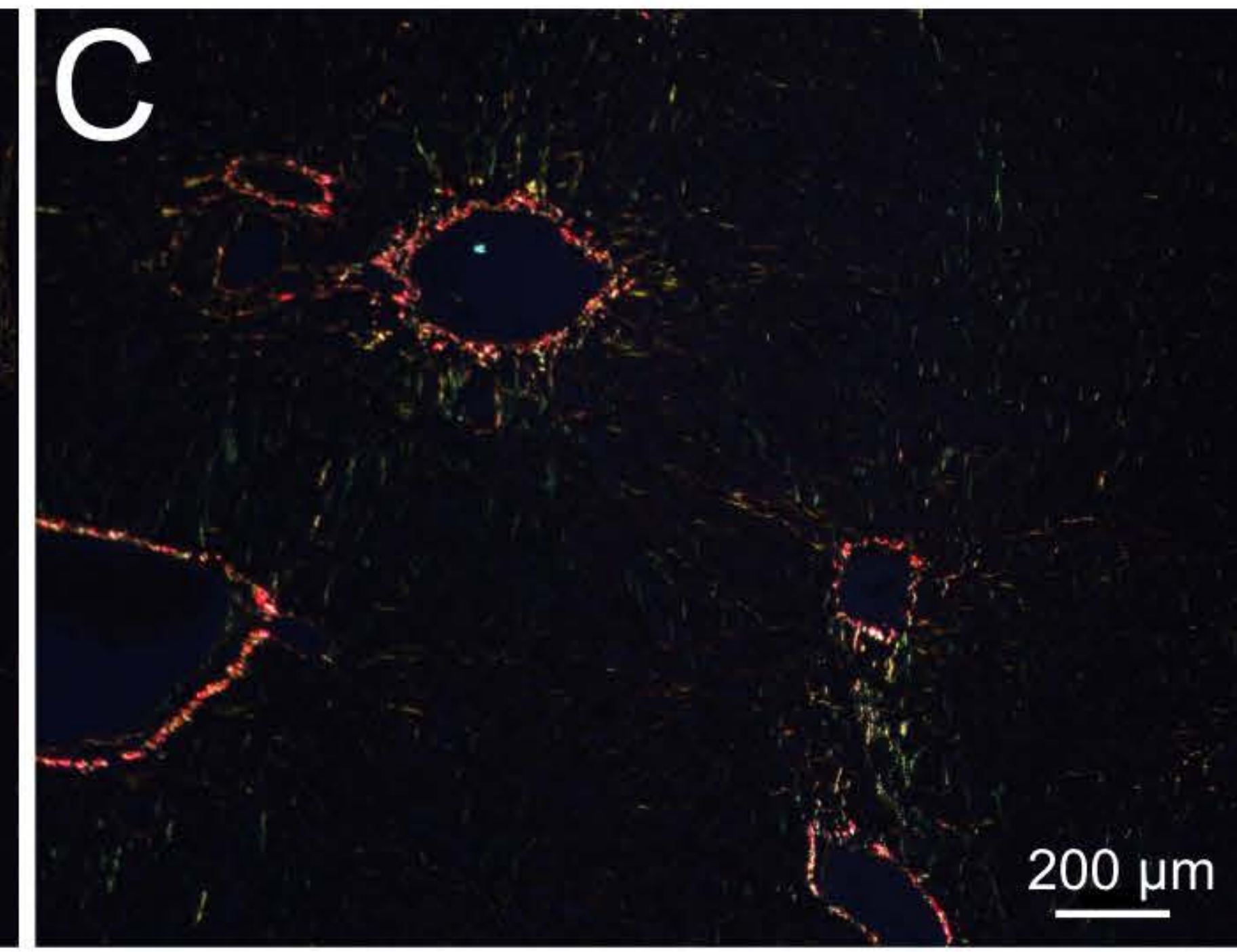


Fig. 4
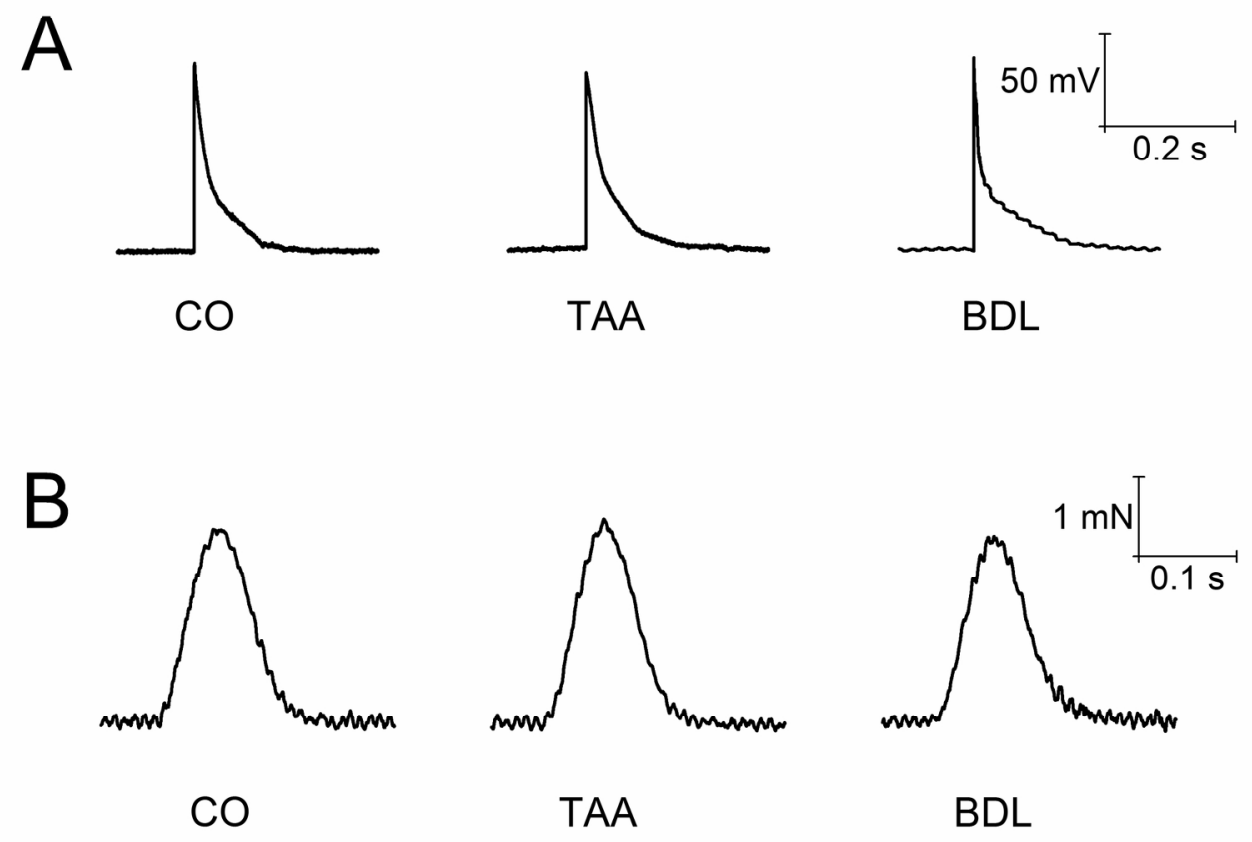

$90 \times 67 \mathrm{~mm}(600 \times 600 \mathrm{DPI})$ 
Fig. 5 proANP
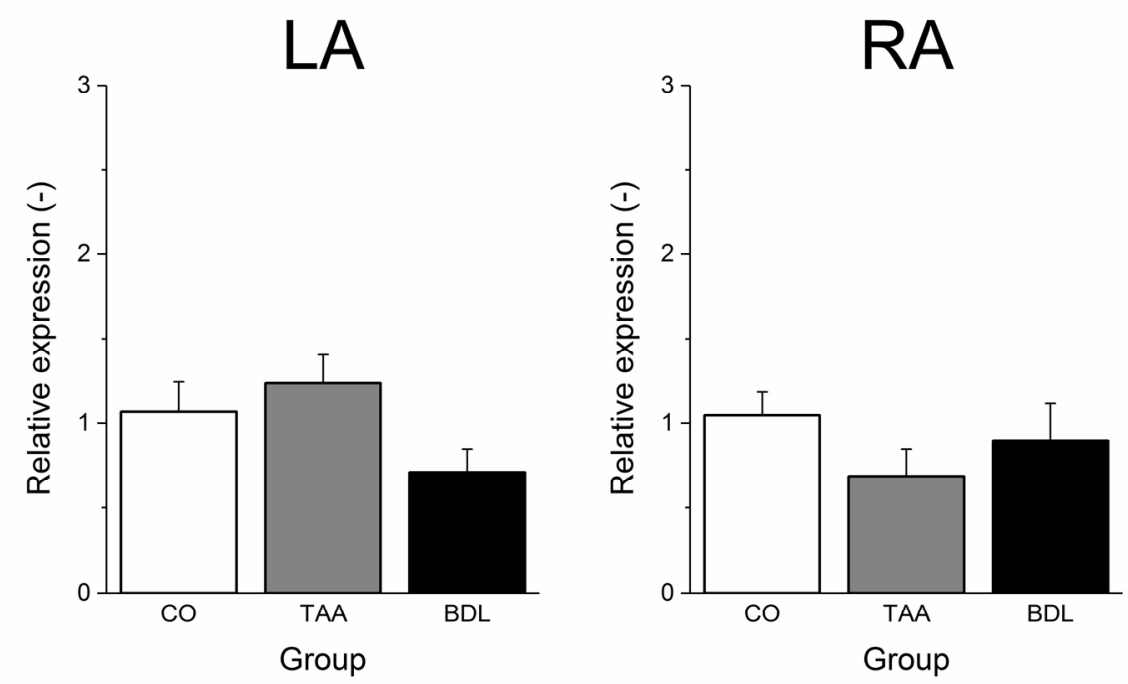

$87 \times 60 \mathrm{~mm}(600 \times 600$ DPI $)$ 
Fig. 6

\section{$\mathrm{TH}$}
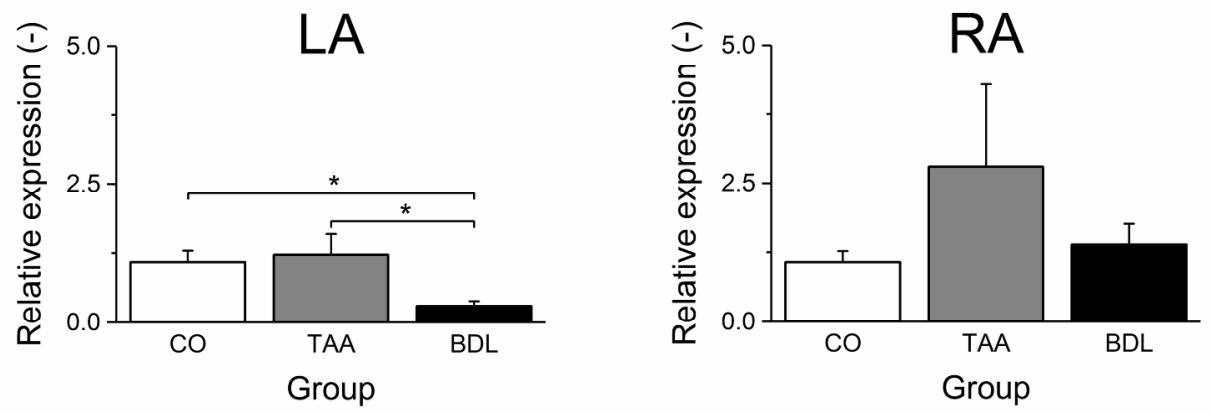

$\mathrm{DBH}$
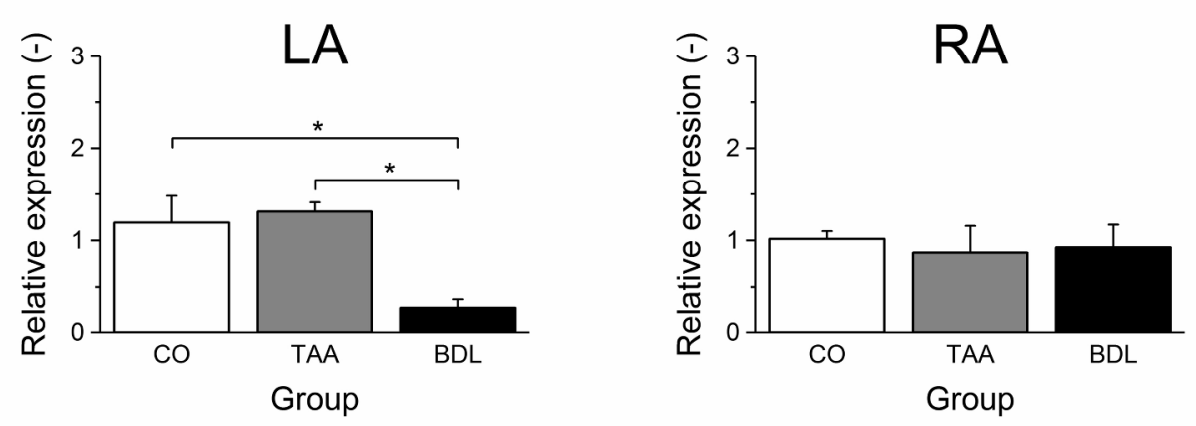

$119 \times 105 \mathrm{~mm}(600 \times 600 \mathrm{DPI})$ 

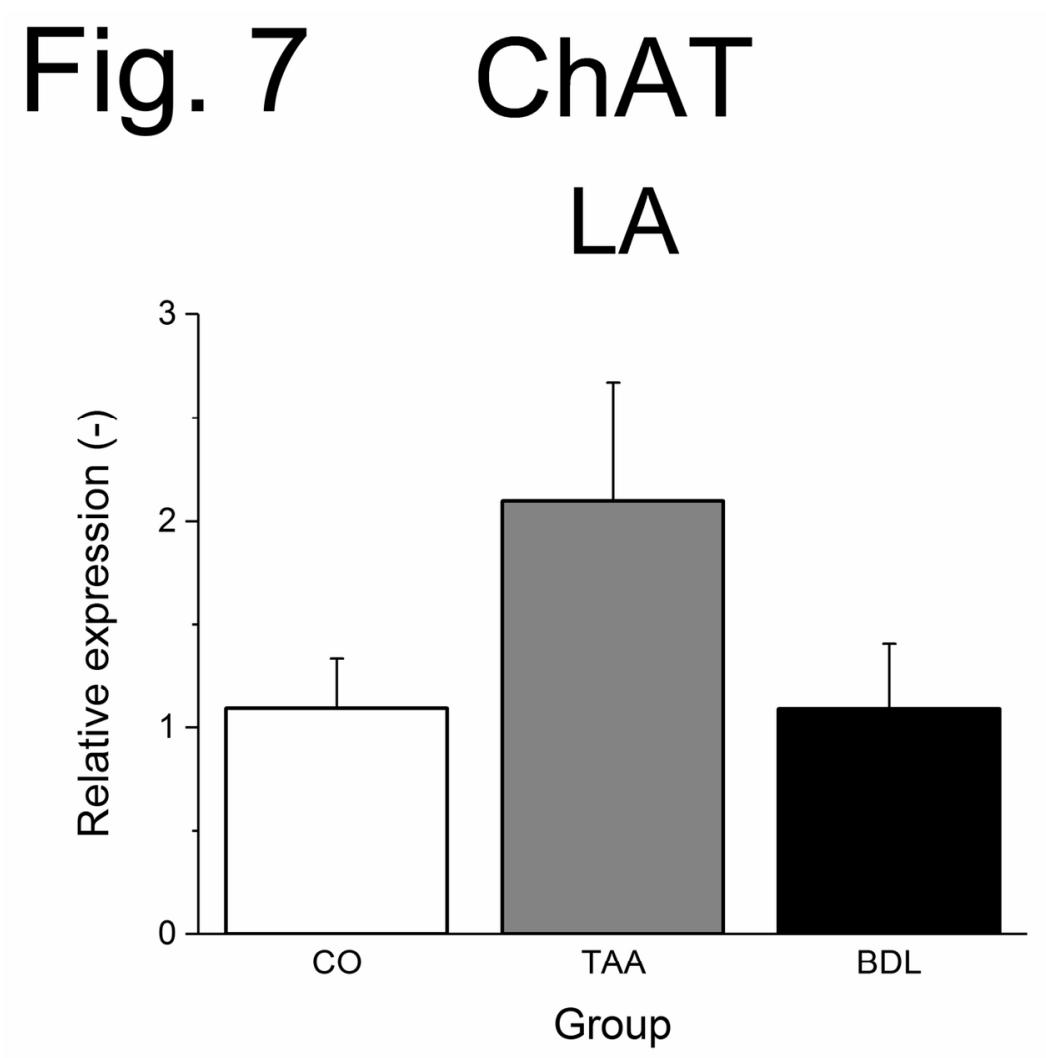

$74 \times 62 \mathrm{~mm}(600 \times 600 \mathrm{DPI})$ 